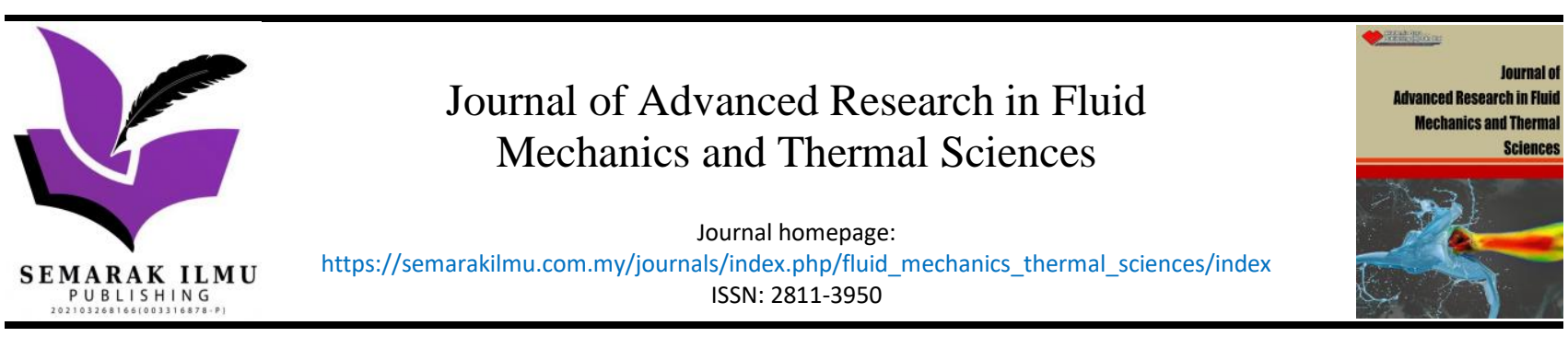

\title{
Investigation of Nanoparticles Shape Effects on Aligned MHD Casson Nanofluid Flow and Heat Transfer with Convective Boundary Condition
}

\author{
Fazillah Bosli ${ }^{1}$, Alia Syafiqa Suhaimi ${ }^{2}$, Siti Shuhada Ishak ${ }^{2}$, Mohd Rijal Ilias $^{2,{ }^{*}}$, Amirah Hazwani Abdul \\ Rahim $^{1}$, Anis Mardiana Ahmad ${ }^{1}$ \\ 1 Faculty of Computer and Mathematical Sciences, Universiti Teknologi MARA Cawangan Kedah, 08400 Merbok, Kedah, Malaysia \\ 2 Faculty of Computer and Mathematical Sciences, Universiti Teknologi MARA Shah Alam, 40450 Shah Alam, Selangor, Malaysia
}

ARTICLE INFO

Article history:

Received 7 October 2021

Received in revised form 9 December 2021

Accepted 15 December 2021

Available online 21 January 2022

\section{Keywords:}

Aligned MHD; Natural Convective Boundary Condition; Casson Nanofluid; Vertical Plate; Nanoparticles Shape

\section{ABSTRACT}

This study focuses on the investigation of aligned MHD natural convection flow and heat transfer of a Casson nanofluid past a vertical plate with convective boundary condition. Casson nanofluid are found in a wide range of commercial and technological applications, including dissolved polymers, biological solutions, paints, asphalts, and glues. The governing partial differential equations (PDE) is transformed to ordinary differential equations (ODE) by using similarity transformation. Keller box method is employed to numerically solve the transformed partial differential equations and then the system is solved by Fortran programming. The results for both the velocity and temperature profiles of Casson nanofluid as well as the skin friction and Nusselt number that are affected by nanoparticles shape factor considering parameters aligned angle of magnetic, interaction of magnetic field, volume fraction of nanoparticles, Local Grashof number, Casson parameter and Biot number are presented graphically and in tabulated form. It is also found that the velocity increases while the temperature decreases when the aligned angle of magnetic, interaction of magnetic field, Casson parameter and Local Grashof number increase. The skin friction and Nusselt number increases for all parameters except for Casson nanofluid parameter. For convective boundary condition, Biot number increases when both velocity and temperature profiles increase. The nanoparticles shape of laminar has the highest velocity and temperature while the spherical shape has the lowest for all parameters.

\section{Introduction}

Nowadays, nanotechnology has played a major role in multifield of heat transfer processes and has made remarkable progress in the energy applications. Nanotechnology is the study and manipulation of matter at extremely small sizes, typically between 1-100 nanometres. Nanotechnologies cover a very wide variety of materials, manufacturing processes and technologies that are used to produce and improve many products people use every day. It is part of the next wave of advances in science and engineering that will transform many industries, including

\footnotetext{
* Corresponding author.

E-mail address: mrijal@uitm.edu.my

https://doi.org/10.37934/arfmts.91.1.155171
} 
aerospace, energy, information technology, medicine, national defence, and transportation. It will allow the production of next generation products that are stronger, lighter, and sturdier than the materials used today in buildings, bridges, aircraft, automobiles, and other applications [1]. This is therefore the reason why most of the fields use nanotechnology. Furthermore, nanotechnology is the process of utilization of metals and oxides. Metals and oxides are also known as nanofluid.

The nanoparticles used in nanofluids are naturally made of metals (Copper, Aluminium), oxides (Titanium Dioxide, Aluminium Oxide, Copper Oxide, Silicon Dioxide), carbides, nitrides, or nonmetals (graphite, carbon nanotubes). Convectional heat transfer fluids, such as water, oil, and ethylene glycol mixtures, have poor heat transfer capability due to their lower thermal conductivity. In general, the thermal conductivity of the metals is three times higher than that of general fluids [2] and thus, it is permissible to combine the two substances to produce a heat transfer medium which behaves like a fluid but has thermal conductivity of the metal. Several theoretical and experimental investigations have been performed to improve the thermal conductivity of these fluids. Choi was the first to introduce nanofluid when conducting research on new coolants and cooling technologies by Reddy et al., [2]. In addition, nanometer-sized particles give better suspension in base fluids and nullifies the clogging effect in flow channels. Kumar and Shriram [3] explain that nanoparticles have more surface area than conventional particles, which greatly enhances the properties of heat transfer and increases the stability of the suspension. Ghosh and Swati [4] also state that since thermal conductivity of nanofluids is very high compared to base fluids, they are used in many energy systems, such as cooling of nuclear systems, radiators, natural convection in enclosures, drawing of copper wires, continuous stretching of plastic films, artificial fibres, hot rolling, etc. Study by Bahiraei et al., [5] showed that the higher thermal conductivity of nanofluids compared to ordinary liquids results in lower thermal resistance, and hence, leads to more significant heat transfer rates. Furthermore, the improvement in thermal conductivity of nanofluids can be correlated with different properties such as volume fraction, material type, size, and shape [6-7].

Nanoparticles shape is also important because it can affect the thermal conductivity of nanofluid. The nanoparticles used in nanofluids are commonly made of metals, oxides, carbides, nitrides, and nonmetals with various shapes including spheres, disks, or rods, etc. [8]. Nanofluids performance not only relies on the type of nanoparticles but also their shapes. Most of researchers usually use nanoparticles of spherical shapes. However, spherical shaped nanoparticles have limited application and significance. Due to this reason Aaiza et al., [9] used non-spherical shaped nanoparticles in their research. To be more specific, they investigated four different types of nanoparticles called cylinder, platelet, blade, and brick. Moreover, non-spherical shaped nanoparticles are revealed to hold a number of key desirable properties to be the main focus of current research, especially in cancer therapy. An empirical analysis of the magnetohydrodynamics and convective heat transfer of nanofluids synthesized by three different shape (brick, platelet, and cylinder) silver (Ag) nanoparticles in water was also examined by Akbar et al., [10]. In a study by Rashid and Adnan [11], they focused on investigating the effects of nanoparticles shape on aluminium oxide $\left(\mathrm{Al}_{2} \mathrm{O}_{3}\right)$-water nanofluid and heat transfer over a non-linear radically stretching sheet with the presence of magnetic field and thermal radiation. They used five different shapes of nanoparticles which are column, sphere, hexahedron, tetrahedron and lamina. Result showed that lamina shapes nanoparticles have greater heat transfer augmentation than other shapes of nanoparticle where temperature distribution of lamina shape nanoparticles are larger than other shapes of nanoparticles. Subsequently, performance of sphere shape nanoparticles is the lowest in terms of heat transfer augmentation. Similarly, there are various study in nanoparticles shape [12-15].

Besides that, heat transfer performance can be enhanced by using Casson nanofluid. Casson fluid can be defined as a non-Newtonian fluid that behaves like elastic solid (shear thinning behavior). In 
other words, with small shear stress it behaves like a solid while it begins to move in case when shear stress higher than yield stress is exerted. Honey, soup, tomato sauce, concentrated fruit juices and jelly are some examples of this kind of fluid. In Casson fluid model, yield shear stress occurs in the constitutive equation and such kind of fluid is considered as a purely viscous fluid with high viscosity. Abbas et al., [16] explain that Casson fluid possesses important applications in biomechanics and polymer processing industry. This model is also used by petroleum engineers to characterize cement slurry and is better suited to predict high shear-rate viscosities when only low and intermediate shear-rate data are available. The Casson fluid is more precise at both very high and very low shear rates. It is also considered to be the best rheological model for blood and chocolate in Mahdy et al. [17]. Raju et al., [18] investigated the impact of induced magnetic field on Casson fluid flow past a vertical plate and found the influence of velocity distribution follows the physical nature of wellknown Newtonian and all other non-Newtonian fluids. A study by Rawi et al., [19] investigated the influence of nanoparticles on the unsteady mixed convection flow of Casson fluid past an inclined stretching sheet. They used Carboxymethyl cellulose solution (CMC) as the base fluid and copper as nanoparticles with the effect of gravity modulation on the flow. Sulochana and Poornima [20] studied about problem of unsteady magnetohydrodynamic flow of non-Newtonian fluid through a vertical plate in the presence of Hall current. A study by Ibrahim et al., [21] examined the three-dimensional MHD mixed convection flow of Casson nanofluid over an exponentially stretching sheet using the impacts of Hall and ion slip currents. In this way, various researchers did the investigation of Casson fluid under different situations [22-25].

The study of the magnetic properties and behaviour of electrically conducting fluids is called Magnetohydrodynamics (MHD). It is also known as magneto-fluid dynamics or hydromagnetic. Magneto is a magnetic field; hydro is water and dynamics is movement. Magnetic fluids, liquids, metals, and mixtures containing water, salt and other electrolytes are examples of materials that can be investigated using MHD. Hannes Alfven was the first person to introduce the term MHD where a sequence of Navier-Stokes equations and Maxwell's equations was applied in MHD to understand the flow behaviour of a fluid with electromagnetic properties by Narender et al., [26]. Asimoni et al., [27] focused on MHD free convective flow of viscous incompressible electrically conducting fluid past a vertical plate and found that when magnetic field strength increases, the velocity of the fluid decreases for both cases. In addition, the temperature of the fluid increases for cooled plate and decreases for heated plate when magnetic field strength increases. Another study by Benharkat and Mohamed [28] examined the wall velocity and the Coriolis force effects on the steady magnetohydrodynamic convective flow past a moving semi-infinite vertical flat plate in a rotating fluid, resulting from buoyancy forces which arise from a coupled phenomenon of temperature and species concentration. Accordingly, there are several studies in MHD recently [29-31].

Convective boundary conditions also play a crucial role in many engineering processes and industries. Sulochana et al., [32] obtained numerical solutions of three dimensional Casson nanofluid due to permeable stretching sheet in the existence of convective boundary condition. Ilias et al., [33] analysed the influences of convective boundary condition on the magnetic nanofluids over a flat vertical plate with the presence of a magnetic field and continued the research by considering the inclined plate [34]. For both problems, they found that that aligned magnetic field parameter influences the total magnetic interaction parameter. The value of the aligned magnetic field has a huge impact on velocity, temperature, skin friction coefficient, and Nusselt number. Another study on convective boundary condition is performed by Tlili et al., [35]. In their study, the forced convective flow of nanofluids over a horizontal plate with a convective boundary condition and a heated line source which are immersed in a Darcy porous medium was analysed. 
Hence, it seems that the influence of both nanoparticle shape effect and Casson nanofluid plays a crucial role in enhancing thermal conductivity of fluids. Therefore, the study on aligned MHD natural convection flow of a Casson nanofluid past a vertical plate with nanoparticles shape effect cannot be overlooked and needs further investigation. This study focuses on the effects of nanoparticles shape factor towards the behaviour of aligned MHD natural convection Casson nanofluid passing a vertical plate with convective boundary condition. Water is used as a base fluid. The base fluid is mixed with nanoparticles (CuO - Copper Oxide). There are five shapes of nanoparticles that are considered, namely sphere, platelet, cylinder, lamina, and brick. The effect of each parameter such as angle of interaction parameter, interaction of magnetic parameter, volume fraction of magnetic nanoparticles parameter, Local Grashof number, Casson nanofluid parameter, nanoparticles shape parameter, and Biot numbers towards velocity profile, temperature profile as well as skin friction, and Nusselt number are analyzed and presented graphically.

\section{Mathematical Formulation}

The mathematical model is considered under the following assumptions and conditions:

- Two-Dimensional laminar steady flow;

- Boundary layer approximation;

- Tiwari and Das model;

- Non-Newtonian Casson nanofluids;

- Aligned Magnetohydrodynamics (MHD);

- Nanoparticles shape factor;

- Convective boundary conditions.

The rheological equation of state for an isotropic and incompressible flow of Casson nanofluid is

$$
\tau_{i j}=\left\{\begin{array}{l}
\left(\mu_{B}+p_{y} / \sqrt{2 \pi}\right) 2 e_{i j}, \pi>\pi_{c} \\
\left(\mu_{B}+p_{y} / \sqrt{2 \pi_{c}}\right) 2 e_{i j}, \pi>\pi_{c}
\end{array}\right.
$$

where $\mu_{B}$ is plastic dynamic viscosity of non-Newtonian fluid, $p_{y}$ is yield stress, $\pi_{c}$ is critical value of this product based on the non-Newtonian model and $\pi$ is the product of the component of deformation rate with itself, namely $\pi=e_{i j} e_{i j}, e_{i j}$ is the $(\mathrm{i}, \mathrm{j})^{\text {th }}$ component of deformation rate [36]. An aligned magnetic field with an acute angle, $\alpha$ as shown in Figure 1 is applied to the flow. It is recognized as a function of the distance from the origin expressed as $B(x)=\frac{B_{0}}{\sqrt{x}}$ with $B_{0} \neq 0$. 


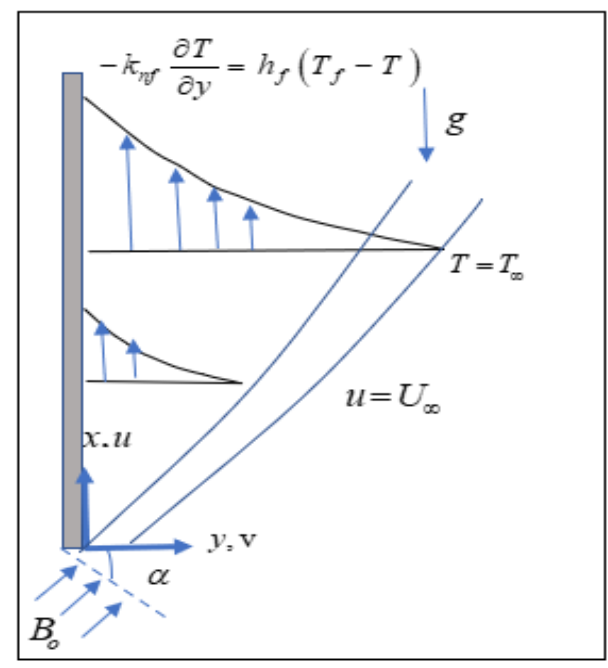

Fig. 1. Physical model and coordinate system of the experiment

Here, $B_{0}$ represent the strength of magnetic field and the coordinate $(x, y)$ along the plate respectively. It is assumed that the base fluids (water) and nanoparticles (CuO-Copper Oxide) are in thermal equilibrium. Assuming that the flow in the laminar boundary layer is two-dimensional and steady, the governing equations are given as:

$\frac{\partial u}{\partial x}+\frac{\partial \mathrm{v}}{\partial y}=0$

$u \frac{\partial u}{\partial x}+\mathrm{v} \frac{\partial u}{\partial y}=\frac{\mu_{n f}}{\rho_{n f}}\left(1+\frac{1}{\beta_{c}}\right) \frac{\partial^{2} u}{\partial y^{2}}+\frac{(\rho \beta)_{n f}}{\rho_{n f}} g\left(T-T_{\infty}\right)-\frac{\sigma B^{2}(x)}{\rho_{n f}} \sin ^{2} \alpha\left(u-U_{\infty}\right)$

$u \frac{\partial T}{\partial x}+\mathrm{v} \frac{\partial T}{\partial y}=\alpha_{n f} \frac{\partial^{2} T}{\partial y^{2}}$

While the boundary conditions used in this study are as follows:

$$
\begin{array}{cll}
u=0, & \mathrm{v}=0, \quad-k_{n f} \frac{\partial T}{\partial y}=h_{f}\left(T_{f}-T\right) & \text { on } \quad y=0 \\
u \rightarrow U_{\infty}, \quad T \rightarrow T_{\infty}, & \text { as } \quad y \rightarrow \infty
\end{array}
$$

where $u$ is the fluid velocity and $\mathrm{V}$ is the normal velocity components along the $\mathrm{x}$-and $\mathrm{y}$-axes. $\alpha$ is the angle of aligned magnetic field, $T_{f}$ is the nanofluid temperature, $T$ is the temperature of the fluid, $T_{\infty}$ is the free stream temperature, $g$ is the gravity acceleration, $U_{\infty}$ is the free stream velocity, $\sigma$ is the electrical conductivity and $\beta_{c}$ is the Casson fluid parameter. The thermophysical relations of nanofluids are as follow [37]. 


$$
\begin{aligned}
& \rho_{n f}=(1-\phi) \rho_{f}+\phi \rho_{s}, \rho_{n f}=(1-\phi) \rho_{f}+\phi \rho_{s}, \mu_{n f}=\frac{\mu_{f}}{(1-\phi)^{2.5}}, \\
& \frac{k_{n f}}{k_{f}}=\frac{k_{s}+(m-1) k_{f}-(m-1) \phi\left(k_{f}-k_{s}\right)}{k_{s}+(m-1) k_{f}+\phi\left(k_{f}-k_{s}\right)} \quad \alpha_{n f}=\frac{k_{n f}}{\left(\rho C_{p}\right)_{n f}} \\
& (\rho \beta)_{n f}=(1-\phi)(\rho \beta)_{f}+\phi(\rho \beta)_{s},
\end{aligned}
$$

where $\rho_{n f}$ is the effective density, $(\rho \beta)_{n f}$ is the thermal expansion coefficient, $\mu_{n f}$ is the effective dynamic viscosity, $\alpha_{n f}$ is the thermal diffusivity of the fluid, $\left(\rho C_{p}\right)_{n f}$ is the heat capacity of the fluid, $k_{n f}$ is the thermal conductivity of the fluid, and $m$ represents the shape factor. It should be noted that the shape factor, $m=3 / \lambda$ where $\lambda$ is the sphericity (the ratio of the surface area of the sphere and the surface area of the real particles with equal volumes). Sphericity of sphere, platelet, cylinder, lamina, and brick are 1.000, 0.526, 0.625, 0.185, and 0.811, respectively. Table 1 shows the thermophysical properties of base fluid [38] and nanoparticles while Table 2 represents the nanoparticles shape factors $(m)[39,40]$.

Table 1

Thermophysical Properties of Base Fluid and Copper Oxide Nanoparticles [38]

\begin{tabular}{lll}
\hline Properties & Base Fluid (Water) & CuO (Copper Oxide) \\
\hline$\rho\left(\mathrm{kg} / \mathrm{m}^{3}\right)$ & 997.1 & 6320 \\
$C_{p}(\mathrm{~J} / \mathrm{kgK})$ & 4179 & 531.8 \\
$k(\mathrm{~W} / \mathrm{mK})$ & 0.613 & 76.5 \\
$\beta \times 10^{-5}$ & 21 & 1.80 \\
$\operatorname{Pr}$ & 6.20 & \\
\hline
\end{tabular}

Table 2

The Nanoparticles Shape Factors (m) [39, 40]

\begin{tabular}{lll}
\hline Nanoparticles Shape & Shape Factor $(\mathrm{m})$ \\
\hline Spherical & 3.0 \\
Platelets & 5.7 \\
Cylindrical & 4.8 \\
Laminar & 16.2 \\
Bricks & 3.7 \\
\hline
\end{tabular}

The continuity equation in (1) is satisfied by introducing stream function $\psi(x, y)$ as shown below, $u=\frac{\partial \psi}{\partial y}, \quad \mathrm{v}=-\frac{\partial \psi}{\partial x}$

The following similarity variables are introduced to solve the governing equations in (1) - (3), 


$$
\eta=\frac{y}{x}\left(\operatorname{Re}_{x}\right)^{\frac{1}{2}}, \quad \psi=v_{f} \sqrt{\operatorname{Re}_{x}} f(\eta), \quad \theta=\frac{T-T_{\infty}}{T_{f}-T_{\infty}},
$$

where $\eta$ is the similarity variable, $\operatorname{Re}_{x}=\frac{U_{\infty} x}{v_{f}}$ refers to Reynolds number, $v_{f}=\frac{\mu_{f}}{\rho_{f}}$ is kinematic viscosity, $f(\eta)$ and $\theta(\eta)$ indicate the non-dimensional stream function and temperature, respectively.

By substituting (5), (6) and (7) into (2) and (3), the following nonlinear systems of ordinary differential equations are obtained:

$$
\begin{aligned}
& {\left[\left(1+\frac{1}{\beta_{c}}\right) f^{\prime \prime \prime}(\eta)\right]+\left[(1-\phi)^{2.5}\left[(1-\phi)+\phi \frac{\rho_{s}}{\rho_{f}}\right] \frac{1}{2} f(\eta) f^{\prime \prime}(\eta)\right]+} \\
& {\left[(1-\phi)^{2.5}\left[(1-\phi)+\phi \frac{(\rho \beta)_{s}}{\rho_{f}}\right] G r_{x} \theta\right]+\left[(1-\phi)^{2.5} M \sin ^{2} \alpha\left(1-f^{\prime}(\eta)\right)\right]=0} \\
& \frac{k_{n f}}{k_{f}} \theta^{\prime \prime}(\eta)+\frac{\operatorname{Pr}}{2}\left((1-\phi)+\phi \frac{\left(\rho C_{p}\right)_{s}}{\left(\rho C_{p}\right)_{f}}\right) f(\eta) \theta^{\prime}(\eta)=0
\end{aligned}
$$

By respecting to (4), the boundary conditions obtained are as follows:

$$
\begin{aligned}
& f(0)=0, \quad f^{\prime}(0)=0, \quad \theta^{\prime}(0)=-B i_{x}(1-\theta(0)), \quad \text { at } \quad \eta=0 \\
& f^{\prime}(\eta) \rightarrow 1 \quad \theta(\eta) \rightarrow 0 \quad \text { as } \eta \rightarrow \infty
\end{aligned}
$$

where primes denote differentiation with respect to $\eta, M=\frac{\sigma B_{0}{ }^{2}}{\rho U_{\infty}}$ is the magnetic interaction parameter, $G r_{x}=\frac{g \beta_{f}\left(T_{f}-T_{\infty}\right) x}{U_{\infty}^{2}}$ is the local Grashof number, $\operatorname{Pr}=\frac{\left(\mu C_{p}\right)}{k_{f}}$ is the Prandtl number and $B i_{x}=\frac{h_{f}}{k_{f}} \sqrt{\frac{x v_{f}}{U_{\infty}}}$ is the local Biot number. In order to have a true similarity solution, the parameters $G r_{x}$ and $B i_{x}$ must be constant and independent of $x$. The discussions of numerical results are based on the skin friction coefficient, $C_{f}$ at the surface of the plate and local Nusselt number, $N u_{x}$ which are defined as:

$$
C_{f}=\frac{\tau_{w}}{\rho_{f} U_{\infty}^{2}}, \quad N u_{x}=\frac{x q_{w}}{k_{f}\left(T_{f}-T_{\infty}\right)}
$$

where $\tau_{w}$ refers to the wall skin friction and $q_{w}$ refers to the heat flux from the plate, which given by:

$$
\tau_{w}=\mu_{n f}\left(1+\frac{1}{\beta_{c}}\right)\left(\frac{\partial u}{\partial y}\right)_{y=0}, \quad q_{w}=-k_{n f}\left(\frac{\partial T}{\partial y}\right)_{y=0}
$$


By substituting (7) and (12) into (11), the solutions obtained are as follows:

$$
\frac{c_{f}}{\operatorname{Re}_{x}^{-\frac{1}{2}}}=\left(1+\frac{1}{\beta_{c}}\right) \frac{1}{(1-\phi)^{2.5}} f^{\prime \prime}(0), \quad \frac{N u_{x}}{\left(\operatorname{Re}_{x}\right)^{\frac{1}{2}}}=\frac{-k_{n f}}{k_{f}} \theta^{\prime}(0)
$$

\section{Numerical Solution}

Eq. (8) and Eq. (9) subject to the boundary conditions (10) are solved numerically using Keller-box method as described in the books by $\mathrm{Na}$ [41] and Cebeci and Bradshaw [42]. The solution is obtained in the following four steps
i. Reduce Eq. (8) and Eq. (9) to first-order system.
ii. Write the difference equations using central differences.
iii. Linearize the resulting algebraic equations by Newton's method and write them in the matrix-vector form.
iv. Solve the linear system by the block tridiagonal elimination technique.

\section{Results and Discussion}

The result explains the effect of the parameters by considering the nanoparticles shape factor. Velocity and temperature profiles of Casson nanofluid that are affected by the parameters is presented using graphs while skin friction and Nusselt number that are affected by parameters are presented in tables. Table 2 presents the comparison of the present analysis with the numerical results reported by Bataller [43], Aziz [44], Ishak et al., [45] and Ramesh et al., [46] for the various values of Biot $\left(B i_{x}\right)$ number. The present results are in good agreement with results from past papers for the validation.

\section{Table 2}

Comparison result of $\theta(0)$ for different values of Biot number, $B i_{x}$ when

\begin{tabular}{|c|c|c|c|c|c|c|c|}
\hline \multirow[t]{2}{*}{$B i_{x}$} & \multicolumn{5}{|c|}{$\operatorname{Pr}=0.72, M=0, G r_{x}=0, m=3, \alpha=0, \beta_{c} \rightarrow \infty, \phi_{1}=0, \frac{k_{n f}}{k_{f}}=1$} & \multicolumn{2}{|c|}{$\begin{array}{l}\operatorname{Pr}=0.72, M=0, G r_{x}=0.5, m=3 \\
\alpha=0, \beta_{c} \rightarrow \infty, \phi_{1}=0, \frac{k_{n f}}{k_{f}}=1\end{array}$} \\
\hline & $\begin{array}{l}\text { Bataller } \\
\text { (2008) }\end{array}$ & $\begin{array}{l}\text { Aziz } \\
(2009)\end{array}$ & $\begin{array}{l}\text { Ishak et al., } \\
\text { (2011) }\end{array}$ & $\begin{array}{l}\text { Ramesh et al., } \\
(2016)\end{array}$ & Present & $\begin{array}{l}\text { Ramesh et al., } \\
\text { (2016) }\end{array}$ & Present \\
\hline 0.05 & 0.1446 & 0.1447 & 0.1446 & 0.1446 & 0.144516 & 0.1388 & 0.138729 \\
\hline 0.1 & - & 0.2528 & 0.2527 & 0.2527 & 0.252536 & 0.2386 & 0.238532 \\
\hline 0.2 & 0.4035 & 0.4035 & 0.4035 & 0.4035 & 0.403240 & 0.3774 & 0.377353 \\
\hline 0.4 & - & 0.5750 & 0.5750 & 0.5750 & 0.574727 & 0.5398 & 0.539794 \\
\hline 0.6 & 0.6699 & 0.6699 & 0.6699 & 0.6699 & 0.669656 & 0.6337 & 0.633716 \\
\hline 0.8 & - & 0.7302 & 0.7301 & 0.7301 & 0.729939 & 0.6954 & 0.695416 \\
\hline 2.0 & 0.7718 & 0.7718 & 0.7718 & 0.7718 & 0.771615 & 0.7392 & 0.739177 \\
\hline 5 & - & 0.9441 & 0.9441 & 0.9441 & 0.944111 & 0.9323 & 0.932312 \\
\hline 10 & 0.9712 & 0.9713 & 0.9712 & 0.9712 & 0.971253 & 0.9648 & 0.964821 \\
\hline
\end{tabular}


In order to study the influences of the aligned angle of magnetic field, $\alpha$, interaction of magnetic field, $M$, volume fraction of nanoparticles, $\phi$, Local Grashof number parameter, $G r_{x}$, Casson paramaters, $\beta_{c}$ and Biot Number, $B i_{x}$ on effect of nanoparticles shape, the numerical results are graphically presented in Figure $2-7$. For the Casson nanofluids, the Prandtl number taken is 6.2 and fit the nondimensional values as follows for numerical computation, $\alpha=90^{\circ}, M=1, \phi=0.1, \beta_{c}=2$, $G r_{x}=0.5$ and $B i_{x}=0.1$, unless otherwise mentioned. In this study, $m$ denotes the shape factor which are sphere $(m=3.0)$, brick $(m=3.7)$, cylinder $(m=4.8)$, platelet $(m=5.7)$ and laminar $(m=16.2)$.

Figure 2-7 show how velocity and temperature profiles change with different values of $\alpha, M, \phi, G r_{x}, \beta_{c}$ and $B i_{x}$, while the numerical value of skin friction coefficient and Nusselt number for nanoparticles shape are shown in Table 3 and Table 4.

Figure 2(a) and 2(b) show the effect of different values of inclined angle of magnetic field, $\alpha$ on the velocity and temperature profile for all nanoparticles shape. It is observed that for every shape of nanoparticles, an increase on $\alpha$ results in an increase in the velocity profile but a decrease in the momentum boundary layer thickness. This is because an increase in the value of $\alpha$ will enhance the applied magnetic field and therefore, pushing the Casson nanofluid towards the plate. When $\alpha=0$ it indicates that there is no magnetic field, but when $\alpha=90^{\circ}$ the aligned magnetic field behaves like a transverse magnetic field and due to changes in the aligned field position of magnetic field, it attracts the nanoparticles. For all nanoparticles shape, as $\alpha$ increases, the velocity profile increases while the temperature profile decreases. The thermal boundary layer thickness also decreases due to the increase of $\alpha$ of all nanoparticles shape. As shown in Table 3 and Table 4, the skin friction coefficient and Nusselt number increase as $\alpha$ increases. In all nanoparticles shape, it is found that nanoparticles shape of laminar has the highest result.

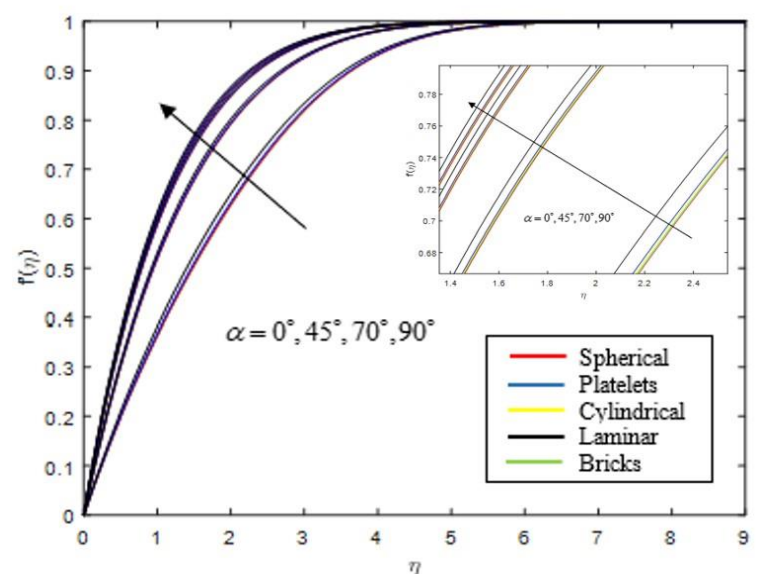

(a)

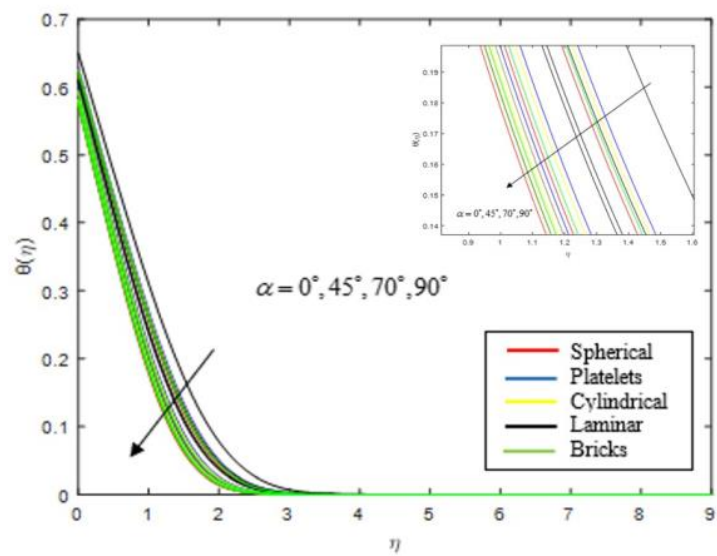

(b)

Fig. 2. Effects of $\alpha$ on (a) velocity profiles and (b) temperature profiles

Figure 3(a) and 3(b) demonstrate the effect of different values of magnetic field, $M$ on velocity and temperature profile for all nanoparticles shape. It is observed that when there is an increase in $M$, the velocity profile increases, and the momentum boundary layer thickness decreases for all nanoparticles shape. When $M=0$, this indicates there is no magnetic force and with the increment of magnetic field value, it pushes the fluid towards the plate and hence, the decrease in momentum boundary layer. An increase in $M$ leads to an increase in Lorentz force and thus, producing more resistance to the transport phenomena. While, the temperature profile of all nanoparticles shape and the thermal boundary layer decrease when $M$ increases. For the skin friction and Nusselt number, 
they increase as $M$ increases, as shown in Table 3 and Table 4. In all nanoparticles shape, it is found that nanoparticles shape of laminar has the highest result.

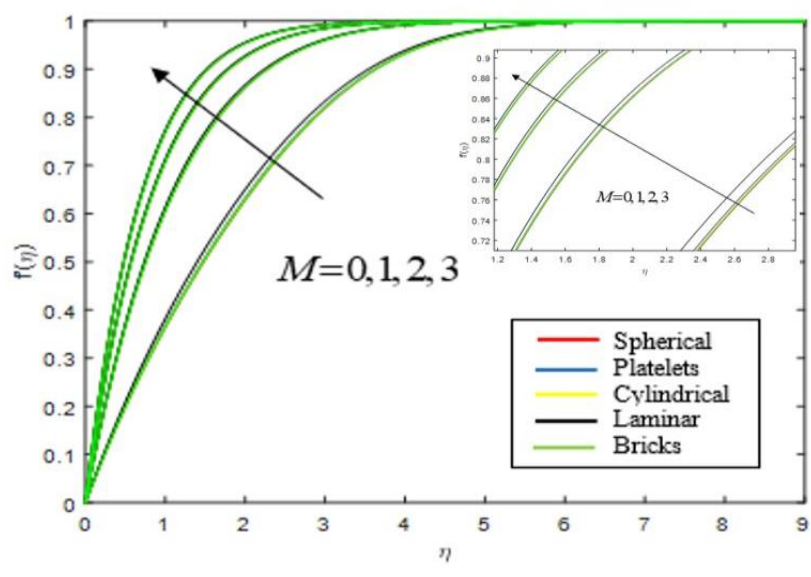

(a)

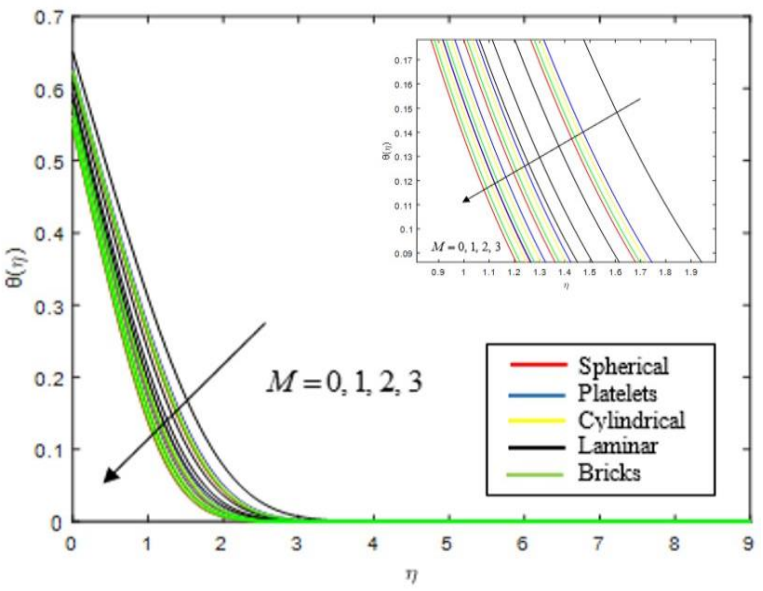

(b)

Fig. 3. Effects of $M$ on (a) velocity profiles and (b) temperature profiles

Figure 4(a) and 4(b) demonstrate the effect of different values volume fraction of nanoparticles, $\phi$, on velocity and temperature profile for all nanoparticles shape. The growth in $\phi$ makes a decrease in the velocity profile for all shapes and increase in the momentum boundary layer thickness. This accompanies with the enhancement of viscosity that tends the velocity to fall. Then, the temperature increases when $\phi$ increases for all shapes of nanoparticles. The increment in $\phi$ also enhances the thermal boundary layer thickness. As shown in Table 3 and Table 4, the skin friction coefficient and Nusselt number increase as $\phi$ increases. It is noticed that laminar nanoparticles shape has the highest skin friction and Nusselt number followed by platelet, cylindrical, bricks and spherical.

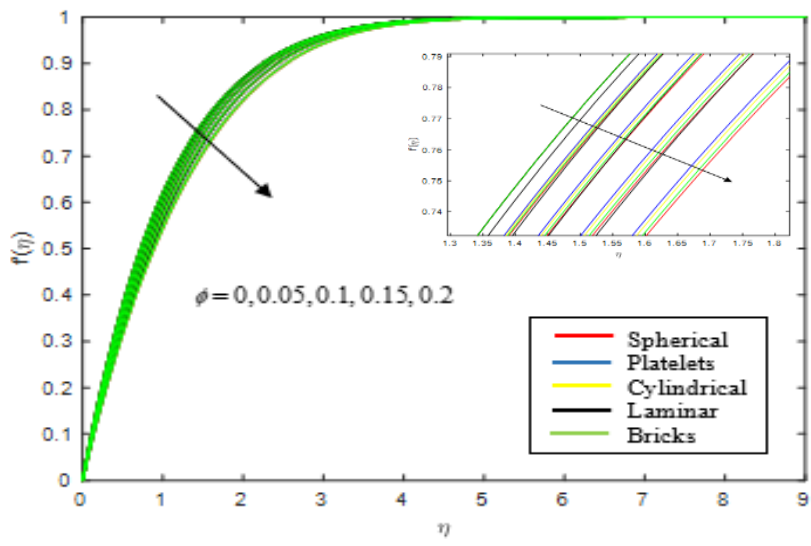

(a)

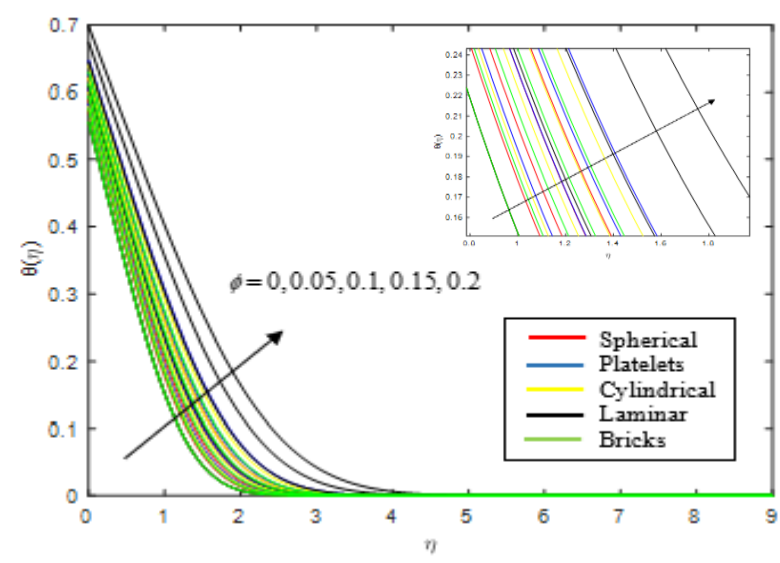

(b)

Fig. 4. Effects of $\phi$ on (a) velocity profiles and (b) temperature profiles 
The effects of $G r_{x}$ on the velocity profiles for Casson nanofluid is depicted in Figure 5(a). It is shown that an increase in the $G r_{x}$ leads to an increase in the velocity profiles. Since $G r_{x}$ is the ratio of the buoyant to the viscous force that acts on a fluid, rising buoyancy forces allow viscosity to decrease and with it the boundary layer of momentum decreases continuously. The effect of $G r_{x}$ on temperature profile is also shown in Figure $5(b)$. The figure shows that the temperature profile decreases when the $G r_{x}$ increases. This is because when the viscosity decreases, the fluid is diluted and increases the thermal boundary layer. Hence, the temperature profiles decrease. Based on Table 3 and Table 4, the skin friction coefficient and Nusselt number increase as $G r_{x}$ increases for all shapes. It is found that laminar nanoparticles shape has the highest skin friction and Nusselt number, while the lowest is nanoparticles shape of spherical.

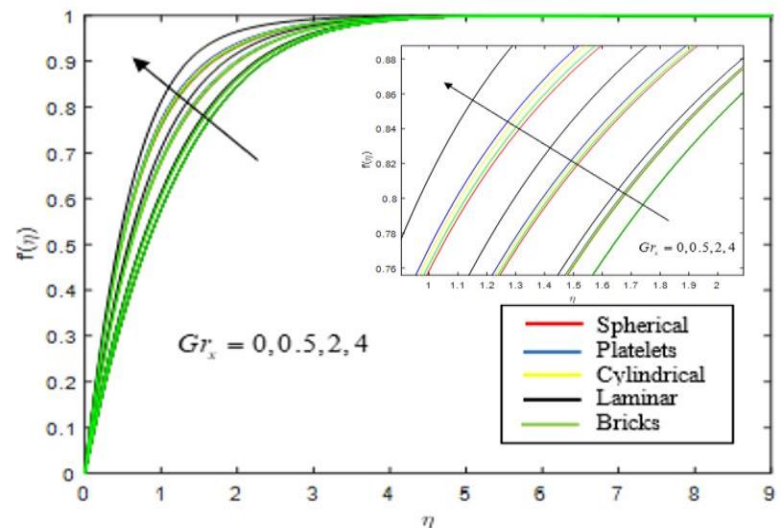

(a)

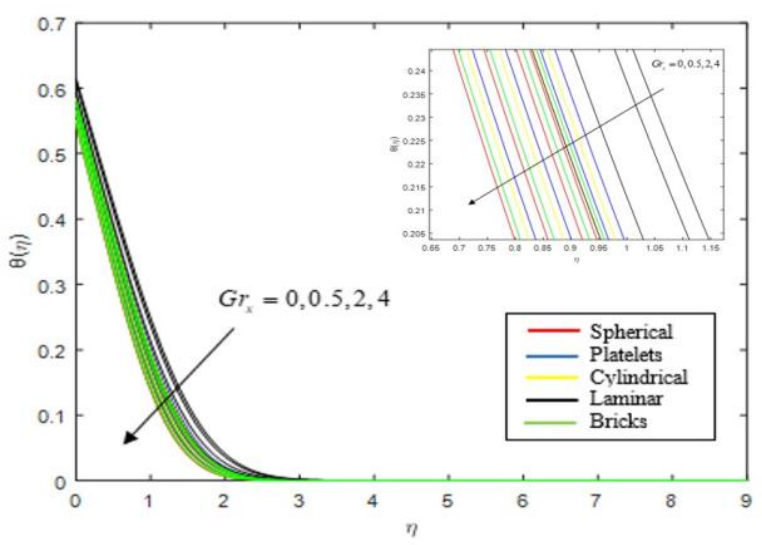

(b)

Fig. 5. Effects of $G r_{x}$ on (a) velocity profiles and (b) temperature profiles

The influence of the Casson nanofluid parameter, $\beta_{c}$ on the nanofluid velocity is shown in Figure 6(a). When Casson nanofluid parameter rises, the nanofluid velocity also rises, while the thickness of boundary layer reduces. It can be easily perceived that, with an increment in the value of Casson nanofluid parameter, the momentum equation tends to the momentum equation of a Newtonian fluid. Hence, nanofluid velocity increases as the effective viscous drag force decreases with the increase in $\beta_{c}$, for higher values of $\beta_{c}$. This is why nanofluid velocity reaches the free stream velocity earlier for a greater value of $\beta_{c}$. Figure $6(\mathrm{~b})$ displays the effect of $\beta_{c}$ on temperature profiles for all nanoparticles shapes. It is noticeable that fluid temperature declines with the increase in $\beta_{c}$ for all shapes. The reason is that an increase in $\beta_{c}$ implies a reduction in yield stress, and consequently, the thickness the thermal boundary layer reduces. The magnitude of skin friction coefficient is decrease while Nusselt number is increase as $\beta_{c}$ increases for all shapes as shown in Table 3 and Table 4. It is found that laminar nanoparticles shape has the highest skin friction and Nusselt number, followed by platelet, cylindrical, bricks and sphere. 


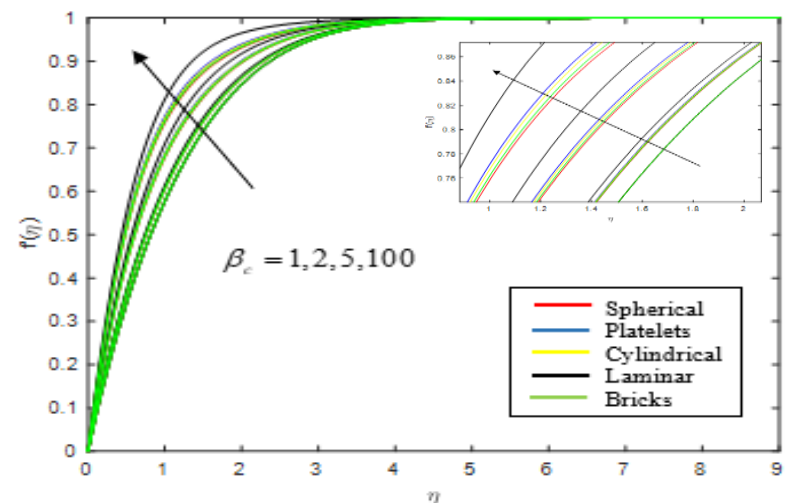

(a)

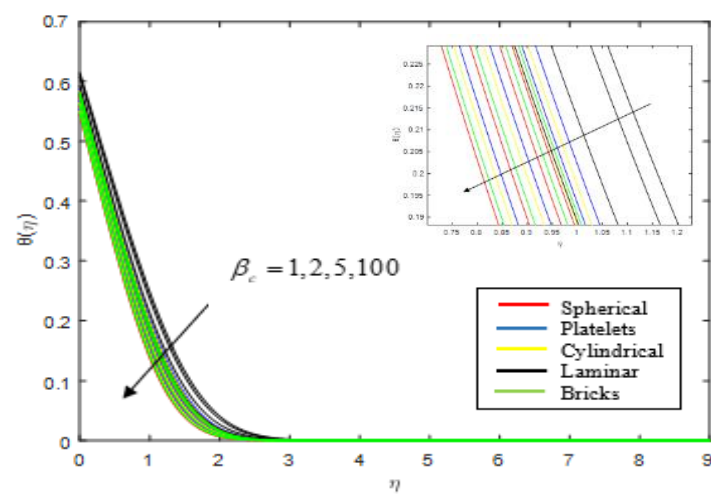

(b)

Fig. 6. Effects of $\beta_{c}$ on (a) velocity profiles and (b) temperature profiles

Based on Figure 7(a), it is shown that the effect of $B i_{x}$ on velocity profile varies according to the shapes of nanoparticles. The figure shows that when there is an increase in $B i_{x}$, the velocity profile increases while the momentum boundary layer decreases for all nanoparticles shape. When $B i_{x}=0$ , there is no convective heat transfer and the velocity would also be low whereas when $B i_{x}$ increases, the buoyancy force becomes stronger as a result of the increase in strength of convective process on the plate. When $B i_{x} \rightarrow \infty$, convective boundary condition problem reduces to constant wall temperature. It is observed in Figure $7(b)$ that as the $B i_{x}$ increases, the temperature profile and the thermal boundary layer also increase for all nanoparticles shape. This is because, with an increase in $B i_{x}$, the thermal resistance of the plate decreases and the convective heat transfer of the plate increases. Table 3 and Table 4 show that the skin friction and Nusselt number increase as the $B i_{x}$ value increases for all nanoparticles shape. It is found that laminar nanoparticles shape has the highest skin friction and Nusselt number, followed by platelet, cylindrical, bricks and sphere.

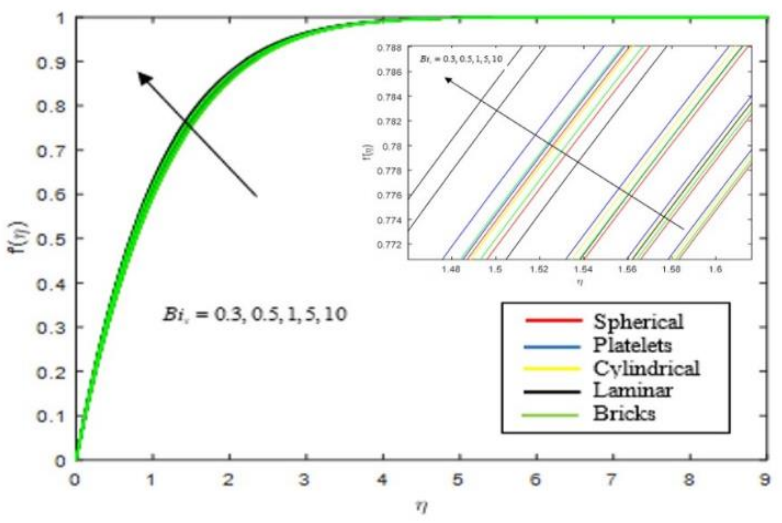

(a)

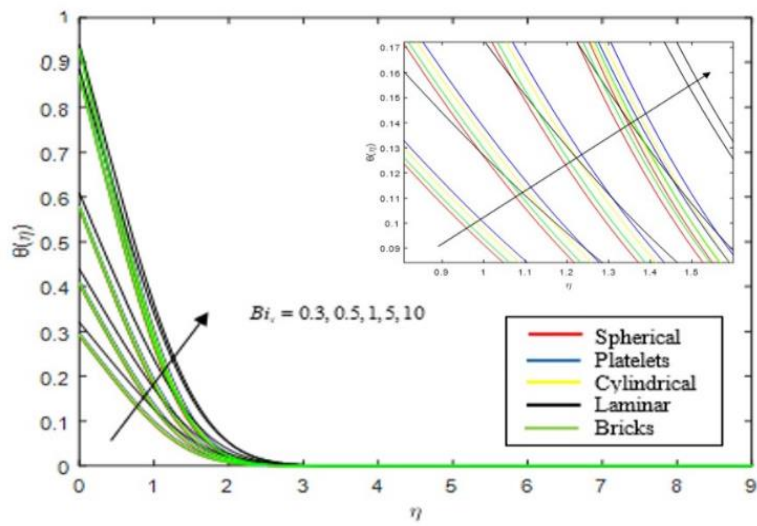

(b)

Fig. 7. Effects of $B i_{x}$ on (a) velocity profiles and (b) temperature profiles 


\section{Table 3}

Variation in skin friction coefficient at different dimensionless parameters for Shapes of Nanoparticles

\begin{tabular}{|c|c|c|c|c|c|c|c|c|c|c|}
\hline \multirow[b]{3}{*}{$\alpha$} & \multirow[b]{3}{*}{$M$} & \multirow[b]{3}{*}{$\phi$} & \multirow[b]{3}{*}{$G r_{x}$} & \multirow[b]{3}{*}{$\beta_{c}$} & \multirow[b]{3}{*}{$B i_{x}$} & \multicolumn{5}{|c|}{ Skin Friction Coefficient } \\
\hline & & & & & & \multicolumn{5}{|c|}{ Shapes of Nanoparticles } \\
\hline & & & & & & $\begin{array}{l}\mathrm{S} \\
m=3\end{array}$ & $\begin{array}{l}\mathrm{B} \\
m=3.7\end{array}$ & $\begin{array}{l}\mathrm{P} \\
m=5.7\end{array}$ & $\begin{array}{l}\mathrm{C} \\
m=4.8\end{array}$ & $\begin{array}{l}\mathrm{L} \\
m=16.2\end{array}$ \\
\hline \multirow{4}{*}{$\begin{array}{l}0^{\circ} \\
45^{\circ} \\
70^{\circ} \\
90^{\circ}\end{array}$} & \multirow{4}{*}{1} & \multirow{4}{*}{0.1} & \multirow{4}{*}{0.5} & \multirow{4}{*}{2} & \multirow{4}{*}{0.1} & 0.737076 & 0.739941 & 0.747630 & 0.744256 & 0.779224 \\
\hline & & & & & & 1.192649 & 1.194639 & 1.199982 & 1.197637 & 1.221920 \\
\hline & & & & & & 1.442733 & 1.444450 & 1.449057 & 1.447036 & 1.467926 \\
\hline & & & & & & 1.510366 & 1.512022 & 1.516463 & 1.514515 & 1.534645 \\
\hline \multirow{4}{*}{$90^{\circ}$} & 0 & \multirow{4}{*}{0.1} & \multirow{4}{*}{0.5} & \multirow{4}{*}{2} & \multirow{4}{*}{0.1} & 0.737076 & 0.739941 & 0.747630 & 0.744256 & 0.779224 \\
\hline & 1 & & & & & 1.510366 & 1.512022 & 1.516463 & 1.514515 & 1.534645 \\
\hline & 2 & & & & & 1.992139 & 1.993461 & 1.997001 & 1.995449 & 2.011417 \\
\hline & 3 & & & & & 2.373132 & 2.374270 & 2.377315 & 2.375981 & 2.389669 \\
\hline \multirow{5}{*}{$90^{\circ}$} & \multirow{5}{*}{1} & 0 & \multirow{5}{*}{0.5} & \multirow{5}{*}{2} & \multirow{5}{*}{0.1} & 1.403183 & 1.403183 & 1.403183 & 1.403183 & 1.403183 \\
\hline & & 0.05 & & & & 1.510366 & 1.512022 & 1.516463 & 1.514515 & 1.534645 \\
\hline & & 0.1 & & & & 1.630294 & 1.633389 & 1.641417 & 1.637942 & 1.671163 \\
\hline & & 0.15 & & & & 1.765464 & 1.769824 & 1.780831 & 1.776116 & 1.818796 \\
\hline & & 0.2 & & & & 1.919035 & 1.924518 & 1.938050 & 1.932305 & 1.982225 \\
\hline \multirow{4}{*}{$90^{\circ}$} & \multirow{4}{*}{1} & \multirow{4}{*}{0.1} & 0 & \multirow{4}{*}{2} & \multirow{4}{*}{0.1} & 1.369309 & 1.369309 & 1.369309 & 1.369309 & 1.369309 \\
\hline & & & 0.5 & & & 1.510366 & 1.512022 & 1.516463 & 1.514515 & 1.534645 \\
\hline & & & 2 & & & 1.899653 & 1.905681 & 1.921842 & 1.914754 & 1.987895 \\
\hline & & & 4 & & & 2.363634 & 2.374648 & 2.404173 & 2.391225 & 2.524812 \\
\hline & & & & 1 & & 1.737376 & 1.739205 & 1.744112 & 1.741959 & 1.764228 \\
\hline $90^{\circ}$ & 1 & 01 & 05 & 2 & 01 & 1.510366 & 1.512022 & 1.516463 & 1.514515 & 1.534645 \\
\hline & 1 & 0.1 & 0.5 & 5 & 0.1 & 1.354798 & 1.356328 & 1.360432 & 1.358632 & 1.377207 \\
\hline & & & & 100 & & 1.245601 & 1.247039 & 1.250893 & 1.249203 & 1.266637 \\
\hline & & & & & 0.3 & 1.441004 & 1.442070 & 1.444952 & 1.443684 & 1.457092 \\
\hline & & & & & 0.5 & 1.468942 & 1.470297 & 1.473946 & 1.472342 & 1.489128 \\
\hline $90^{\circ}$ & 1 & 0.1 & 0.5 & 2 & 1 & 1.510366 & 1.512022 & 1.516463 & 1.514515 & 1.534645 \\
\hline & & & & & 5 & 1.581794 & 1.583622 & 1.588498 & 1.586364 & 1.608072 \\
\hline & & & & & 10 & 1.596336 & 1.598145 & 1.602968 & 1.600858 & 1.622289 \\
\hline
\end{tabular}

(S-Spherical, B- Bricks, C- Cylindrical, P- Platelets, L- Laminar) 


\section{Table 4}

Variation of Nusselt number at different dimensionless parameters for Shapes of Nanoparticles

\begin{tabular}{|c|c|c|c|c|c|c|c|c|c|c|}
\hline \multirow{4}{*}{$\alpha$} & \multirow{4}{*}{$M$} & \multirow{4}{*}{$\phi$} & \multirow{4}{*}{$G r_{x}$} & \multirow{4}{*}{$\beta_{c}$} & \multirow{4}{*}{$B i_{x}$} & \multicolumn{5}{|c|}{ Nusselt Number } \\
\hline & & & & & & \multicolumn{5}{|c|}{ Shapes of Nanoparticles } \\
\hline & & & & & & $S$ & B & $\mathrm{C}$ & $P$ & $\mathrm{~L}$ \\
\hline & & & & & & $m=3$ & $m=3.7$ & $m=4.8$ & $m=5.7$ & $m=16.2$ \\
\hline $0^{\circ}$ & \multirow{4}{*}{1} & \multirow{4}{*}{0.1} & \multirow{4}{*}{0.5} & \multirow{4}{*}{2} & \multirow{4}{*}{0.1} & 0.438477 & 0.449140 & 0.465513 & 0.478579 & 0.612542 \\
\hline $45^{\circ}$ & & & & & & 0.475506 & 0.486930 & 0.504460 & 0.518436 & 0.661180 \\
\hline $70^{\circ}$ & & & & & & 0.489831 & 0.501580 & 0.519607 & 0.533976 & 0.680569 \\
\hline $90^{\circ}$ & & & & & & 0.493236 & 0.505065 & 0.523211 & 0.537675 & 0.685207 \\
\hline \multirow{4}{*}{$90^{\circ}$} & 0 & \multirow{4}{*}{0.1} & \multirow{4}{*}{0.5} & \multirow{4}{*}{2} & \multirow{4}{*}{0.1} & 0.438477 & 0.449140 & 0.465513 & 0.478579 & 0.612542 \\
\hline & 1 & & & & & 0.493236 & 0.505065 & 0.523211 & 0.537675 & 0.685207 \\
\hline & 2 & & & & & 0.513378 & 0.525682 & 0.544553 & 0.559591 & 0.712789 \\
\hline & 3 & & & & & 0.525648 & 0.538244 & 0.557563 & 0.572956 & 0.729666 \\
\hline \multirow{5}{*}{$90^{\circ}$} & \multirow{5}{*}{1} & 0 & & & & 0.444294 & 0.444294 & 0.444294 & 0.444294 & 0.444294 \\
\hline & & 0.05 & & & & 0.493236 & 0.505065 & 0.523211 & 0.537675 & 0.685207 \\
\hline & & 0.1 & 0.5 & 2 & 0.1 & 0.544277 & 0.567952 & 0.603964 & 0.632421 & 0.912862 \\
\hline & & 0.15 & & & & 0.597699 & 0.633312 & 0.687080 & 0.729254 & 1.133878 \\
\hline & & 0.2 & & & & 0.653823 & 0.701534 & 0.773083 & 0.828840 & 1.351897 \\
\hline \multirow{4}{*}{$90^{\circ}$} & \multirow{4}{*}{1} & \multirow{4}{*}{0.1} & 0 & \multirow{4}{*}{2} & \multirow{4}{*}{0.1} & 0.486882 & 0.498453 & 0.516197 & 0.530333 & 0.674226 \\
\hline & & & 0.5 & & & 0.493236 & 0.505065 & 0.523211 & 0.537675 & 0.685207 \\
\hline & & & 2 & & & 0.508969 & 0.521413 & 0.540518 & 0.555760 & 0.711853 \\
\hline & & & 4 & & & 0.525024 & 0.538068 & 0.558109 & 0.574108 & 0.738457 \\
\hline \multirow{4}{*}{$90^{\circ}$} & \multirow{4}{*}{1} & \multirow{4}{*}{0.1} & \multirow{4}{*}{0.5} & 1 & & 0.481642 & 0.493161 & 0.510832 & 0.524917 & 0.668564 \\
\hline & & & & 2 & 01 & 0.493236 & 0.505065 & 0.523211 & 0.537675 & 0.685207 \\
\hline & & & & 5 & 0.1 & 0.502118 & 0.514183 & 0.532693 & 0.547447 & 0.697940 \\
\hline & & & & 100 & & 0.508899 & 0.521145 & 0.539931 & 0.554906 & 0.707648 \\
\hline & & & & & 0.3 & 0.246175 & 0.252826 & 0.263072 & 0.271275 & 0.356627 \\
\hline & & & & & 0.5 & 0.344645 & 0.353535 & 0.367207 & 0.378131 & 0.490836 \\
\hline $90^{\circ}$ & 1 & 0.1 & 0.5 & 2 & 1 & 0.493236 & 0.505065 & 0.523211 & 0.537675 & 0.685207 \\
\hline & & & & & 5 & 0.756653 & 0.772407 & 0.796496 & 0.815627 & 1.007758 \\
\hline & & & & & 10 & 0.811385 & 0.827750 & 0.852758 & 0.872609 & 1.071481 \\
\hline
\end{tabular}

(S-Spherical, B- Bricks, C- Cylindrical, P- Platelets, L- Laminar)

\section{Conclusions}

The present study investigates the numerical of aligned MHD natural convection flow and heat transfer of a Casson nanofluid past a vertical plate with convective boundary condition. The results obtained regarding the influences of the aligned angle of magnetic field, $\alpha$, interaction of magnetic field, $M$, volume fraction of nanoparticles, $\phi$, Local Grashof number parameter, $G r_{x}$, Casson parameters, $\beta_{c}$ and Biot Number, $B i_{x}$ on the effect of nanoparticles shape are as follows example

i. The velocity increases due to the increasing of $\alpha, M, B_{c}$ and $G r_{x}$.

ii. The temperature profiles decrease due to the increasing of $\alpha, M, B_{c}$ and $G r_{x}$.

iii. An increase in $\phi$ depicts a decrement in the velocity profile but a rise in the temperature profile.

iv. When the value of $B i_{x}$ increases, the velocity and temperature profiles also increase.

v. The nanoparticles shape with the highest velocity and temperature profiles is laminar followed by platelet, cylindrical, bricks, and spherical.

vi. The skin friction and Nusselt number increase due to the rise in $\alpha, M, \phi, G r_{x}$ and $B i_{x}$ except for $\beta_{c}$. 


\section{Acknowledgement}

The authors extend their appreciation to Universiti Teknologi MARA Cawangan Kedah for funding this work through Geran Dana Kecemerlangan under grant number 600-UiTMKDH (PJI. 5/4/1) (9/2018).

\section{References}

[1] Salem, A. M. "Nanofluid: New fluids by nanotechnology". Thermophysical Properties of Complex Materials, (2020). https://doi:10.5772/intechopen.86784

[2] Reddy, P. Sudarsana, Ali J. Chamkha, and Ali Al-Mudhaf. "MHD heat and mass transfer flow of a nanofluid over an inclined vertical porous plate with radiation and heat generation/absorption." Advanced Powder Technology 28, no. 3 (2017): 1008-1017. https://doi.org/10.1016/i.apt.2017.01.005.

[3] Kumar, Nishant, and Shriram S. Sonawane. "Experimental study of $\mathrm{Fe}_{2} \mathrm{O}_{3} /$ water and $\mathrm{Fe}_{2} \mathrm{O}_{3} /$ ethylene glycol nanofluid heat transfer enhancement in a shell and tube heat exchanger." International Communications in Heat and Mass Transfer 78 (2016): 277-284. https://doi.org/10.1016/i.icheatmasstransfer.2016.09.009

[4] Ghosh, Sudipta, and Swati Mukhopadhyay. "MHD slip flow and heat transfer of Casson nanofluid over an exponentially stretching permeable sheet." International Journal of Automotive \& Mechanical Engineering 14, no. 4 (2017). https://doi.org/10.15282/ijame.14.4.2017.14.0375

[5] Bahiraei, Mehdi, Ali Monavari, and Hossein Moayedi. "Second law assessment of nanofluid flow in a channel fitted with conical ribs for utilization in solar thermal applications: Effect of nanoparticle shape." International Journal of Heat and Mass Transfer 151 (2020):119387. https://doi.org/10.1016/j.ijheatmasstransfer.2020.119387

[6] Kandasamy, R., Nur Atikah bt Adnan, and Radiah Mohammad. "Nanoparticle shape effects on squeezed MHD flow of water-based $\mathrm{Cu}, \mathrm{Al}_{2} \mathrm{O}_{3}$ and SWCNTs over a porous sensor surface." Alexandria engineering journal 57, no. 3 (2018): 1433-1445. https://doi.org/10.1016/i.aej.2017.03.011

[7] Rawi, Noraihan Afiqah, Mohd Rijal Ilias, Zaiton Mat Isa, and Sharidan Shafie. "Effect of Gravity Modulation on Mixed Convection Flow of Second Grade Fluid with Different Shapes of Nanoparticles." Malaysian Journal of Fundamental and Applied Sciences 13, no. 2 (2017). http://doi.10.11113/mjfas.v13n2.643

[8] Ellahi, R., M. Hassan, A. Zeeshan, and Ambreen A. Khan. "The Shape Effects of Nanoparticles Suspended in HFE7100 over Wedge with Entropy Generation and Mixed Convection." Applied Nanoscience 6, no. 5 (2015): 641-651. http://doi:10.1007/s13204-015-0481-z

[9] Aaiza, Gul, Ilyas Khan, and Sharidan Shafie. "Energy transfer in mixed convection MHD flow of nanofluid containing different shapes of nanoparticles in a channel filled with saturated porous medium." Nanoscale Research Letters 10, no. 1 (2015): 1-14. http://doi:10.1186/s11671-015-1144-4.

[10] Akbar, Noreen Sher, Dharmendra Tripathi, and Osman Anwar Bég. "MHD convective heat transfer of nanofluids through a flexible tube with buoyancy: a study of nano-particle shape effects." Advanced Powder Technology 28, no. 2 (2017): 453-462. http://doi:10.1016/i.apt.2016.10.018.

[11] Rashid, Umair, and Adnan Ibrahim. "Impacts of nanoparticle shape on $\mathrm{Al}_{2} \mathrm{O}_{3}$-water nanofluid flow and heat transfer over a non-linear radically stretching sheet." Advances in Nanoparticles 9, no. 01 (2020): 23. https://doi.org/10.4236/anp.2020.91002.

[12] Khan, Ilyas. "Shape effects of MoS2 nanoparticles on MHD slip flow of molybdenum disulphide nanofluid in a porous medium." Journal of Molecular Liquids 233 (2017): 442-451. http://doi:10.1016/j.molliq.2017.03.009.

[13] Sheikholeslami, Mohsen. "Magnetic field influence on $\mathrm{CuO}-\mathrm{H}_{2} \mathrm{O}$ nanofluid convective flow in a permeable cavity considering various shapes for nanoparticles." International Journal of Hydrogen Energy 42, no. 31 (2017): 1961119621.http://doi:10.1016/j.ijhydene.2017.06.121.

[14] Arani, Ali Akbar Abbasian, Soroush Sadripour, and Saeideh Kermani. "Nanoparticle shape effects on thermalhydraulic performance of boehmite alumina nanofluids in a sinusoidal-wavy mini-channel with phase shift and variable wavelength." International Journal of Mechanical Sciences 128 (2017): 550-563. http://doi:10.1016/i.ijmecsci.2017.05.030.

[15] Maheshwary, P. B., C. C. Handa, K. R. Nemade, and S. R. Chaudhary. "Role of nanoparticle shape in enhancing the thermal conductivity of nanofluids." Materials Today: Proceedings $28 \quad$ (2020): 873-878. http://doi:10.1016/i.matpr.2019.12.315.

[16] Abbas, Z., M. Sheikh, and S. S. Motsa. "Numerical solution of binary chemical reaction on stagnation point flow of Casson fluid over a stretching/shrinking sheet with thermal radiation." Energy 95 (2016): 12-20. http://doi:10.1016/j.energy.2015.11.039. 
[17] Mahdy, A., Ali J. Chamkha, and Hossam A. Nabwey. "Entropy analysis and unsteady MHD mixed convection stagnation-point flow of Casson nanofluid around a rotating sphere." Alexandria Engineering Journal 59, no. 3 (2020): 1693-1703. http://doi:10.1016/i.aej.2020.04.028.

[18] Raju, M. C., and Raju KVS. "MHD Casson fluid flow through a vertical plate." Journal of Computational \& Applied Research in Mechanical Engineering (JCARME) 9, no. 2 (2020): 343-350. 10.22061/jcarme.2019.4015.1476

[19] Rawi, N. A., M. R. Ilias, Y. J. Lim, Z. M. Isa, and S. Shafie. "Unsteady mixed convection flow of Casson fluid past an inclined stretching sheet in the presence of nanoparticles." In Journal of Physics: Conference Series, vol. 890, no. 1, p. 012048. IOP Publishing, 2017. http://doi:10.1088/1742-6596/890/1/012048.

[20] Sulochana, C., and M. Poornima. "Unsteady MHD Casson fluid flow through vertical plate in the presence of Hall current." SN Applied Sciences 1, no. 12 (2019): 1-14. https://doi.org/10.1007/s42452-019-1656-0.

[21] Ibrahim, Wubshet, and Temesgen Anbessa. "Three-Dimensional MHD Mixed Convection Flow of Casson Nanofluid with Hall and Ion Slip Effects." Mathematical Problems in Engineering 2020 (2020): 1-15. http://doi:10.1155/2020/8656147.

[22] Nagarani, P. "Peristaltic transport of a Casson fluid in an inclined channel." Korea-Australia Rheology Journal 22, no. 2 (2010): 105-111. http://doi:10.1007/BF03178376

[23] Vajravelu, K., S. Sreenadh, P. Devaki, and K. V. Prasad. "Peristaltic pumping of a Casson fluid in an elastic tube." Journal of Applied Fluid Mechanics 9, no. $4 \quad$ (2016): 1897-1905. http://doi:10.18869/acadpub.jafm.68.235.24695

[24] El-Zahar, Essam R., Abd El Nasser Mahdy, Ahmed M. Rashad, Wafaa Saad, and Laila F. Seddek. "Unsteady MHD Mixed Convection Flow of Non-Newtonian Casson Hybrid Nanofluid in the Stagnation Zone of Sphere Spinning Impulsively." Fluids 6, no. 6 (2021): 197. http://doi:10.3390/fluids6060197

[25] Akter, Mst Sonia, Mohammad Rafiqul Islam, Md Tusher Mollah, and Md Mahmud Alam. "Hall effects on Casson fluid flow along a vertical plate." In AIP Conference Proceedings, vol. 2121, no. 1, p. 040004. AIP Publishing LLC, 2019. doi:10.1063/1.5115875.

[26] Narender, Ganji, Kamatam Govardhan, and Gobburu Sreedhar Sarma. "Magnetohydrodynamic stagnation point on a Casson nanofluid flow over a radially stretching sheet." Beilstein Journal of Nanotechnology 11, no. 1 (2020): 1303-1315. http://doi:10.3762/bjnano.11.114.

[27] Asimoni, Nor Raihan Mohamad, Nurul Farahain Mohammad, Abdul Rahman Mohd Kasim, and Sharidan Shafie. "MHD free convective flow past a vertical plate." In Journal of Physics: Conference Series, vol. 890, no. 1, p. 012009. IOP Publishing, 2017. doi:10.1088/1742-6596/890/1/012009.

[28] Benharkat, Zohra, and Mohamed Najib Bouaziz. "MHD Rotating Fluid Past a Semi-Infinite Vertical Moving Plate: Coriolis Force and Wall Velocity Effects." Journal of Advanced Research in Fluid Mechanics and Thermal Sciences 60, no. 1 (2019): 38-51.

[29] Noranuar, Wan Nura'in Nabilah, Ahmad Qushairi Mohamad, Sharidan Shafie, Ilyas Khan, Lim Yeou Jiann, and Mohd Rijal Ilias. "Non-coaxial rotation flow of MHD Casson nanofluid carbon nanotubes past a moving disk with porosity effect." Ain Shams Engineering Journal (2021). In Press. https://doi.org/10.1016/j.asej.2021.03.011

[30] Ilias, Mohd Rijal, Noraihan Afiqah Rawi, N. H. A. Raji, and Sharidan Shafie. "Unsteady aligned MHD boundary layer flow and heat transfer of magnetic nanofluid past a vertical plate plate with leading edge accretion." ARPN J. Eng. Appli. Sci 13, no. 1 (2018): 340-351.

[31] Ilias, Mohd Rijal, Noraihan Afiqah Rawi, and Sharidan Shafie. "MHD free convection flow and heat transfer of ferrofluids over a vertical flat plate with aligned and transverse magnetic field." Indian J. Sci. Technol 9, no. 7 (2016). http://doi.10.17485/ijst/2016/v9i36/97347.

[32] Sulochana, C., G. P. Ashwinkumar, and N. Sandeep. "Similarity solution of 3D Casson nanofluid flow over a stretching sheet with convective boundary conditions." Journal of the Nigerian Mathematical Society 35, no. 1 (2016): 128-141. https://doi.org/10.1016/i.jnnms.2016.01.001

[33] Ilias, Mohd Rijal, Noraihan Afiqah Rawi, and Sharidan Shafie. "Natural convection of ferrofluid from a fixed vertical plate with aligned magnetic field and convective boundary condition." Malaysian Journal of Fundamental and Applied Sciences 13, no. 3 (2017): 224-229. https://doi.org/10.11113/mjfas.v13n3.651

[34] Ilias, Mohd Rijal, Noraihan Afiqah Rawi, and Sharidan Shafie. "Steady aligned MHD free convection of Ferrofluids flow over an inclined plate." Journal of Mechanical Engineering (JMechE) 14, no. 2 (2017): 1-15.

[35] Tlili, Iskander, Masoud Rabeti, Mostafa Safdari Shadloo, and Zahra Abdelmalek. "Forced convection heat transfer of nanofluids from a horizontal plate with convective boundary condition and a line heat source embedded in porous media." Journal of Thermal Analysis \& Calorimetry 141, no. 5 (2020): 2081-2094. https://doi.org/10.1007/s10973-020-09473-6

[36] Baby Rani, C. H., K. Kranthi Kumar, and A. V. Papa Rao. "MHD Casson Fluid Flow along Inclined Plate with Hall and Aligned Magnetic Effects." Frontiers in Heat and Mass Transfer (FHMT) 17 (2021). http://doi: 10.5098/hmt.17.2 
[37] Hayat, Tanzila, and S. Nadeem. "Heat transfer enhancement with Ag-CuO/water hybrid nanofluid." Results in physics 7 (2017): 2317-2324. http://doi.10.1016/j.rinp.2017.06.034.

[38] Tippa, Sowmya, Marneni Narahari, and Rajashekhar Pendyala. "Unsteady natural convection flow of nanofluids past a semi-infinite isothermal vertical plate." In AIP Conference Proceedings, vol. 1787, no. 1, p. 020014. AIP Publishing LLC, 2016. doi:10.1063/1.4968063.

[39] Sheikholeslami, M., and M. M. Bhatti. "Forced convection of nanofluid in presence of constant magnetic field considering shape effects of nanoparticles." International Journal of Heat and Mass Transfer 111 (2017): 10391049. http://doi.10.1016/i.ijheatmasstransfer.2017.04.070.

[40] Akbar, Noreen Sher, and Adil Wahid Butt. "Ferromagnetic effects for peristaltic flow of Cu-water nanofluid for different shapes of nanosize particles." Applied Nanoscience 6, no. $3 \quad$ (2016): $379-385$. https://doi.org/10.1007/s13204-015-0430-x

[41] Na, T. Y. (1979). Computational methods in engineering boundary value problem.

[42] Cebeci, Tuncer, and Peter Bradshaw. Physical and computational aspects of convective heat transfer. Springer Science \& Business Media, 2012.

[43] Bataller, Rafael Cortell. "Radiation effects for the Blasius and Sakiadis flows with a convective surface boundary condition." Applied Mathematics and Computation 206, no. $2 \quad$ (2008): $832-840$. https://doi.org/10.1016/j.amc.2008.10.001

[44] Aziz, Abdul. "A similarity solution for laminar thermal boundary layer over a flat plate with a convective surface boundary condition." Communications in Nonlinear Science and Numerical Simulation 14, no. 4 (2009): 1064-1068. https://doi.org/10.1016/i.cnsns.2008.05.003

[45] Ishak, Anuar, Nor Azizah Yacob, and Norfifah Bachok. "Radiation effects on the thermal boundary layer flow over a moving plate with convective boundary condition." Meccanica 46, no. $4 \quad$ (2011): 795-801. https://doi.org/10.1007/s11012-010-9338-4

[46] Ramesh, G. K., A. J. Chamkha, and B. J. Gireesha. "Boundary layer flow past an inclined stationary/moving flat plate with convective boundary condition." Afrika Matematika 27, no. 1-2 (2016): 87-95. https://doi.org/10.1007/s13370-015-0323-x 